\title{
Characterization of nanos1 Homolog in the Olive Flounder, Paralichthys olivaceus (Temminck \& Schlegel, 1846)
}

\author{
Xungang $\operatorname{Tan}^{1,2, *} \mathbb{C}$, Yulei Sui ${ }^{1,2,3}$, Meijie $\mathrm{Li}^{1,2,3}$, Shuang Jiao ${ }^{1,2}$, Zhihao $\mathrm{Wu}^{1,2}$, Feng \\ You $^{1,2}$
}

${ }^{1}$ Key Laboratory of Experimental Marine Biology, Center for Ocean Mega-Science, Institute of Oceanology, Chinese Academy of Sciences, Qingdao 266071, P.R. China

${ }^{2}$ Laboratory for Marine Biology and Biotechnology, Pilot National Laboratory for Marine Science and Technology (Qingdao), Qingdao 266071, P.R. China

${ }^{3}$ University of Chinese Academy of Sciences, Beijing 10049, P.R. China

\section{Article History}

Received 23 January 2019

Accepted 04 November 2019

First Online (Early view webde

yayınlanma tarihi)

\section{Corresponding Author}

Tel.: 0086-532-82898551

E-mail: tanx@qdio.ac.cn

\section{Keywords}

Abdomen

Gonads

Phylogenetic analysis

Teleost fish

\begin{abstract}
The nanos gene family plays a critical role during germline development in a wide array of organisms. The characteristics of the gene structure and function of nanos1, a nanos homolog, vary from species to species. Herein, we isolated the full-length cDNA of a nanos1 homolog in the olive flounder, Paralichthys olivaceus, and analyzed its expression pattern. The full-length cDNA sequence of the olive flounder nanos1 has 1215 base pairs (bp) and contains a 112 bp $5^{\prime}$-untranslated region, a 684 bp open reading frame that encodes a 228 AA peptide, and a 419 bp $3^{\prime}$ - untranslated region. Phylogenetic analyses showed that the Nanos 1 homolog of the olive flounder grouped with the nanos1 of teleost fish. We detected nanos1 mRNA in all stages of embryogenesis using RT-PCR analyses. Our whole mount in situ hybridization results showed that nanos1 was expressed in the diencephalon, midbrain, hindbrain, nose, medulla oblongata, retina, abdomen, and somatic gonadal cells. Our data indicate that the expression pattern of nanos 1 is not consistent from species to species, supporting that nanos1 had different functions in different organisms.
\end{abstract}

\section{Introduction}

The nanos protein is an RNA-binding protein containing two $\mathrm{CCHC}$ zinc-finger motifs (Hiroshi et al., 2009) that plays a critical role during germline development in a wide variety of organism. The function of the nanos gene family in primordial germ cell (PGC) migration and survival during early embryogenesis is evolutionarily conserved (Shen \& Xie, 2010). However, the processes regulated by nanos vary among species and between different homologs (Ye et al., 2012). There is only one Nanos homolog in Drosophila melanogaster, while Caenorhabditis elegans and all the vertebrates have three nanos homologs. The Nanos homolog of Drosophila was shown to be involved in controlling germ cell migration, somatic cell fate suppression in the germline, and stem cell self-renewal maintenance
(Asaoka-Taguchi, Yamada, Nakamura, Hanyu, \& Kobayashi, 1999; Hayashi, Hayashi, \& Kobayahsi, 2004; Wang \& Lin, 2004). In C. elegans, nanos homologs (nos1 and nos-2) were required to regulate PGCs migrating into the somatic gonad and for the maintenance of germline cell viability during its larval development, while nos-3 was involved in controlling the spermoocyte switch (Kraemer et al., 1999; Subramaniam \& Seydoux, 1999). In mouse, Nanos3 was responsible for maintaining PGCs, whereas Nanos2 is involved in preventing germ cells from entering meiosis (Tsuda et al., 2003; Tsuda, Kiso, \& Saga, 2006; Suzuki, Tsuda, \& Saga, 2007).

Besides germline cells, nanos transcripts were also widely present in multipotent cells and somatic tissues. In invertebrates, such as the sea anemone, nanos was expressed in multiple somatic cell types during early 
embryonic development (Extavour, Pang, Matus, \& Martindale, 2005). In Hydra magnipapillata, nanos transcripts were found in multipotent interstitial cells, which developed into germ cells and a variety of somatic cell types (Mochizuki, Sano, Kobayashi, NishimiyaFujisawa, \& Fujisawa, 2000). In vertebrates, such as humans, NANOS1 was expressed in numerous tissues, like the heart, brain, liver, ovary, spleen, and testis (Julaton \& Reijo Pera, 2011). In mouse, Nanos1 transcripts were detected in the central nervous system and the seminiferous tubules of mature testes and (Haraguchi et al., 2003). The teleost fish medaka, has two nanos1 paralogues, nanos $1 a$ and nanos $1 b$. nanos $1 a$ was expressed in the cerebellum, diencephalon, hypothalamus, caudal wall of the mesencephalon, nose, peripheral ganglia, and the somatic cells surrounding the oocytes after the initiation of sexual differentiation. nanos $1 b$ was detected in the branchial arch, mesencephalon, nose, optic tectum, otic vesicle, retina, and parts of the telencephalon (Aoki, Nakamura, Ishikaw, \& Tanaka, 2009). The adult Chinese sturgeon (Acipenser sinensis) expressed nanos1 mRNA in the cerebellum, heart, hypothalamus, intestines, kidney, medulla oblongata, muscle, ovary, pituitary gland, spleen, and telencephalon midbrain (Ye et al., 2012). Despite the broad characterization of the expression and function of members of the nanos gene family, there is little information about the expression pattern of nanos1 during embryonic development.

The olive flounder (Paralichthys olivaceus) is a native species to the Western Pacific, that is distributed from the Sea of Okhotsk to the southeastern Russian shores, and along the Japanese coast to the South China Sea. It is a commercially important marine fish in East Asia that has been cultured for more than 20 years. Li et al. (2015) detected nanos3 transcripts in migrating PGCs and germ cells of the olive flounder. However, the function of these transcripts and the expression pattern of other nanos homologs in the olive flounder remains unknown. In this study, we aimed to characterize the nanos1 olive flounder homolog and to elucidate whether the function of the nanos subfamily members is conserved among vertebrates.

\section{Materials and Methods}

\section{Fish Culture and Sample Collection}

Olive flounders were cultured under controlled conditions (a light/dark cycle of $14 \mathrm{~h} \mathrm{/} 10 \mathrm{~h}$, a temperature of $15 \pm 1^{\circ} \mathrm{C}$, and aerated seawater) at a fish farm in Rongcheng, China. The fish were fed with fresh fish diet twice daily. Fertilized eggs were obtained by artificial insemination (Jiao et al., 2015), and cultured at $15 \pm 1^{\circ} \mathrm{C}$ in a $1 \mathrm{~m}^{3}$ tank with aerated seawater. The developmental stages were identified by monitoring the embryos with a stereoscope every $15 \mathrm{~min}$ and comparing the observations to those of a previous study
(Tian, Chen, Yan, \& Ji, 2004). To isolate the RNA, the samples (embryos or tissue) were rapidly frozen in liquid nitrogen after Trizol reagent (Invitrogen, Waltham, MA, USA) was added. The samples were stored at $-80^{\circ} \mathrm{C}$. For in situ hybridization, eggs at different stages were fixed in paraformaldehyde (PFA) $(4 \%, 1 \times \mathrm{PBS})$ at $4^{\circ} \mathrm{C}$ overnight. Then, PFA was replaced by methanol (100\%), and the samples were stored at $-20^{\circ} \mathrm{C}$ (Li et al., 2015).

\section{RNA Isolation and Cdna Synthesis}

Total RNA was extracted from samples (flounder gonads and different developmental stage embryos) using Trizol (Invitrogen, Waltham, MA, USA), following the manufacturer's instructions. The total RNA was digested with RQ1 RNase-free DNase (Promega Corporation, Madison, $\mathrm{WI}, \mathrm{USA})\left(30 \mathrm{~min}\right.$ at $\left.37^{\circ} \mathrm{C}\right)$, to remove DNA. M-MLV reverse transcriptase (Promega Corporation) was used to synthesize the First-strand cDNA with oligo-dT from $1 \mu \mathrm{g}$ total RNA, following the enzyme instructions.

\section{Sequence Alignment and Phylogenetic Analysis}

Clustal Omega (http: //www.ebi.ac.uk/Tools) were used to do alignment with amino acid sequence of Nanos homologs from flounder and other species (Sievers et al., 2011). The evolutionary history was deduced by the neighbor-joining method (Saitou \& Nei, 1987), and a phylogenetic tree was built using MEGA6 (https://www.megasoftware. net/, Tamura, Stecher, Peterson, Filipski, \& Kumar, 2013). The phylogeny was tested by the bootstrap method (10000 replicates) (Felsenstein, 1985). The Poisson correction method was used to calculate evolutionary distances (Zuckerkandl \& Pauling, 1965). There were 25 amino acid sequences in the analysis; all positions with gaps and missing data were completely deleted. There was a total of 86 positions in the final dataset.

\section{Isolation of the Olive Flounder Nanos1}

The coding region of the olive flounder nanos1 gene was isolated by reverse transcription polymerase chain reaction (RT-PCR) from olive flounder ovary cDNA. RT-PCR was performed using Taq DNA polymerase (CoWin Biotech, Beijing, China) and the primers nanos1Fw and nanos1-Rw (Table 1). After purification, the PCR products were ligated into the PEASY-T3 vector (TransGen Biotech Inc., Beijing, China) and sequenced.

The SMARTer ${ }^{\mathrm{TM}}$ RACE CDNA Amplification kit (Clontech, Mountain View, CA, USA) was used to construct the SMARTer 5'RACE and $3^{\prime}$ RACE CDNA libraries. The 5'UTR and 3'UTR of nanos1 were isolated using the RACE program following the manufacturer's instructions, using specific primers (nanos1-5-1 and nanos1-5-2 for the 5'UTR; nanos1-3-1 and nanos1-3-2 for the 3'UTR; Table 1), and the universal primer mix (UPM) (Clontech, Mountain View, CA, USA). After the 
purification, the PCR products were ligated into the PEASY-T3 vector and sequenced.

\section{Reverse Transcription-PCR (RT-PCR)}

RT-PCR using Taq DNA polymerase was conducted on embryos of different developmental stages to test the expression of nanos1 during embryogenesis. The final volume of the PCR reaction was $25 \mu \mathrm{l}$ and contained $4 \mu \mathrm{L}$ of cDNA (1:50 dilution) as a template, and the primers nanos1-Fw and nanos1-Rw (Table 1). Beta-actin (B-actin) was used as a control. The primers for this reaction were 6 -actin-Fw and 8 -actin-Rw (Table 1$)$. The PCR program was: denaturation at $94^{\circ} \mathrm{C}$ for $5 \mathrm{~min}, 45$ cycles of denaturation at $94^{\circ} \mathrm{C}$ for $1 \mathrm{~min}$, renaturation at $55^{\circ} \mathrm{C}$ for $30 \mathrm{~s}$, and elongation at $72^{\circ} \mathrm{C}$ for $1 \mathrm{~min}$; with a final elongation step of $72^{\circ} \mathrm{C}$ for $10 \mathrm{~min}$.

\section{Whole-Mount in Situ Hybridization}

An antisense RNA probe was synthesized by in vitro transcription with T7 RNA polymerase (ThermoFisher Scientific, Waltham, MA, USA), the linearized plasmid containing a nanos1 cDNA fragment and a DIG RNA labeling mix (Roche Applied Science, Mannheim, Germany). The probe was purified using SigmaSpin ${ }^{\mathrm{TM}}$ Sequencing Reaction Clean-Up (Sigma-Aldrich, St. Louis, MO, USA). Whole-mount in situ hybridization was conducted according to a previously described method (Zhang, Tan, Zhang, \& Xu, 2006), with some modifications. The pre-hybridization and hybridization temperature was $70^{\circ} \mathrm{C}$. Polyvinylalcohol (Final concentration $2 \%$ ) was added to the alkaline buffer containing NBT/BCIP (Roche). After staining, the stained embryos were fixed in $4 \%$ PFA overnight at $4^{\circ} \mathrm{C}$. After changing the storage solution to PBST buffer, the embryos were incubated in glycerol to take the photographs. We performed cross frozen sections of 10 $15 \mu \mathrm{m}$ with some frozen embryos (Jiao et al., 2015). All digital images were taken using a Leica DM LB2 microscope with a Leica DFC420C (Leica, Wetzlar, Germany).

\section{Results}

Table 1 Sequences of the primers used for PCR.

\section{Isolation and Characterization of Olive Flounder Nanos1}

The full-length olive flounder nanos1 cDNA has 1215 base pairs (bp) and is composed by a 112 bp 5'untranslated region (UTR), a 684 bp open reading frame (ORF), and a 419 bp 3'-UTR. The olive flounder nanos1 homolog encodes a protein of 227 AA with an RNAbinding domain, and a conserved zinc-finger domain (Figure 1A). The deduced amino acid sequence of the olive flounder Nanos1 showed higher similarity to the Nanos1 from teleost fish than to those of other species. For example, flounder Nanos1 was $58 \%$ and $44 \%$ identical to medaka (Oryzias latipes) Nanos1a and Nanos1b, respectively; and 64\% identical to the Chinese sturgeon (Acipenser sinensis) Nanos1. In contrast, the olive flounder Nanos 1 showed only $31.8 \%$ and $29.4 \%$ identity to the NANOS1 of human and mouse, respectively (data not shown). The results from our phylogenetic analysis indicated that the olive flounder Nanos1 homolog grouped with Nanos1 homologs of other teleost fishes and its closest relative was the Chinese sturgeon Nanos1 (Figure 1B).

\section{Spatiotemporal Pattern of Nanos1 Transcripts During Olive Flounder Embryo Development}

The expression patterns of nanos1 during embryogenesis were observed by whole mount in situ hybridization (Figure 2). Nanos1 was expressed in the head at $75 \%$ of the epiboly stage (Figure 2 A). From $90 \%$ of the epiboly stage, the nanos1 transcript was detected in the diencephalon and hindbrain (data not shown). At the $24.25 \mathrm{hpf}$ stage, the transcript was also detected in the trunk neural crest, which develops into the medulla oblongata (Figure 2C). At the $25.75 \mathrm{hpf}$ stage, nanos 1 mRNA expression was also detected in the retina (Figure 2D). At the $28.75 \mathrm{hpf}$ stage, the transcript was detected in the nose and weakly in the olfactory bulb (Figure 2E). At the 35.75hpf stage, the expression was also observed in the branchial arch (Figure 2F). At the 50.75hpf stage, the transcript was detected in the abdomen (Figure $2 \mathrm{H}$ ). Finally, at the hatching stage, the nanos1 transcript was present in the somatic gonadal cells (Figure 2I).

The expression levels of nanos1 during embryo development were analyzed by reverse transcription-

\begin{tabular}{lc}
\hline Primer name & Sequence $\left(5^{\prime}\right.$ to $\left.{ }^{\prime}\right)$ \\
\hline nanos1-5-1 & GGAGTCGTCTTCCAAACCCAGGGTGG \\
nanos1-5-2 & GGTGGCTTTAAGAGACTCGGTGATGG \\
nanos1-3-1 & CGGCAGAGTCCTGTGTCCCATCCTCC \\
nanos1-3-2 & CCTCCGTGCGTACACCTGCCCCCTCTG \\
nanos1-Fw & ATGGATTTCTTGGATCACAG \\
nanos1-Rw & TCAGAAGCTTTTCAGCCTTTT \\
$\beta$-actin-Fw & ACTACCTCATGAAGATCCTG \\
-actin-Rw & TTGCTGATCCACATCTGCTG \\
\hline
\end{tabular}




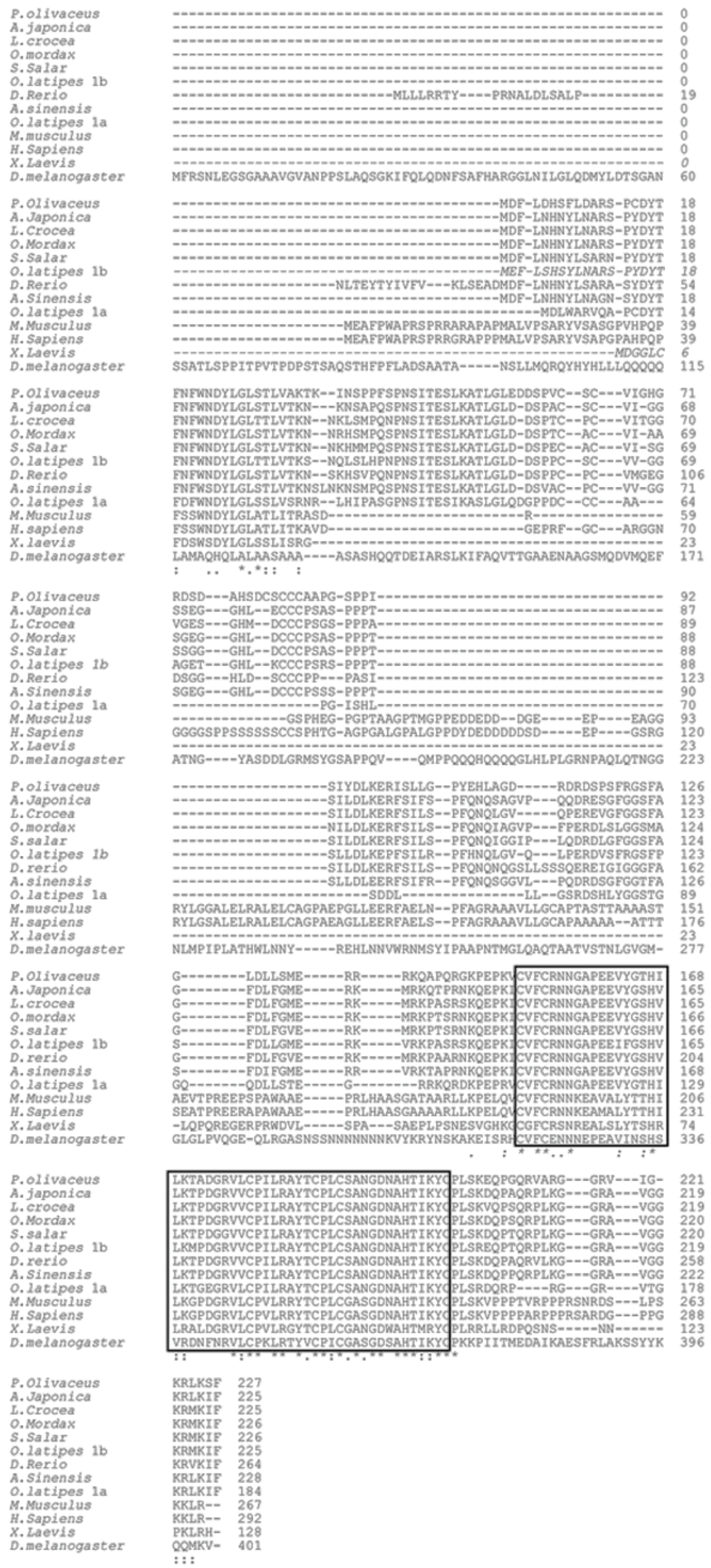

Figure 1A. Comparison of olive flounder (Paralichthys olivaceus) nanos1 protein and nanos homologs in other species.

An asterisk (*) indicates positions that have a single, fully conserved residue. A colon (:) indicates conservation between groups with strongly similar properties; A period (.) indicates conservation between groups with weakly similar properties. An open rectangle $(\square)$ indicates the presence of a zinc finger domain. 


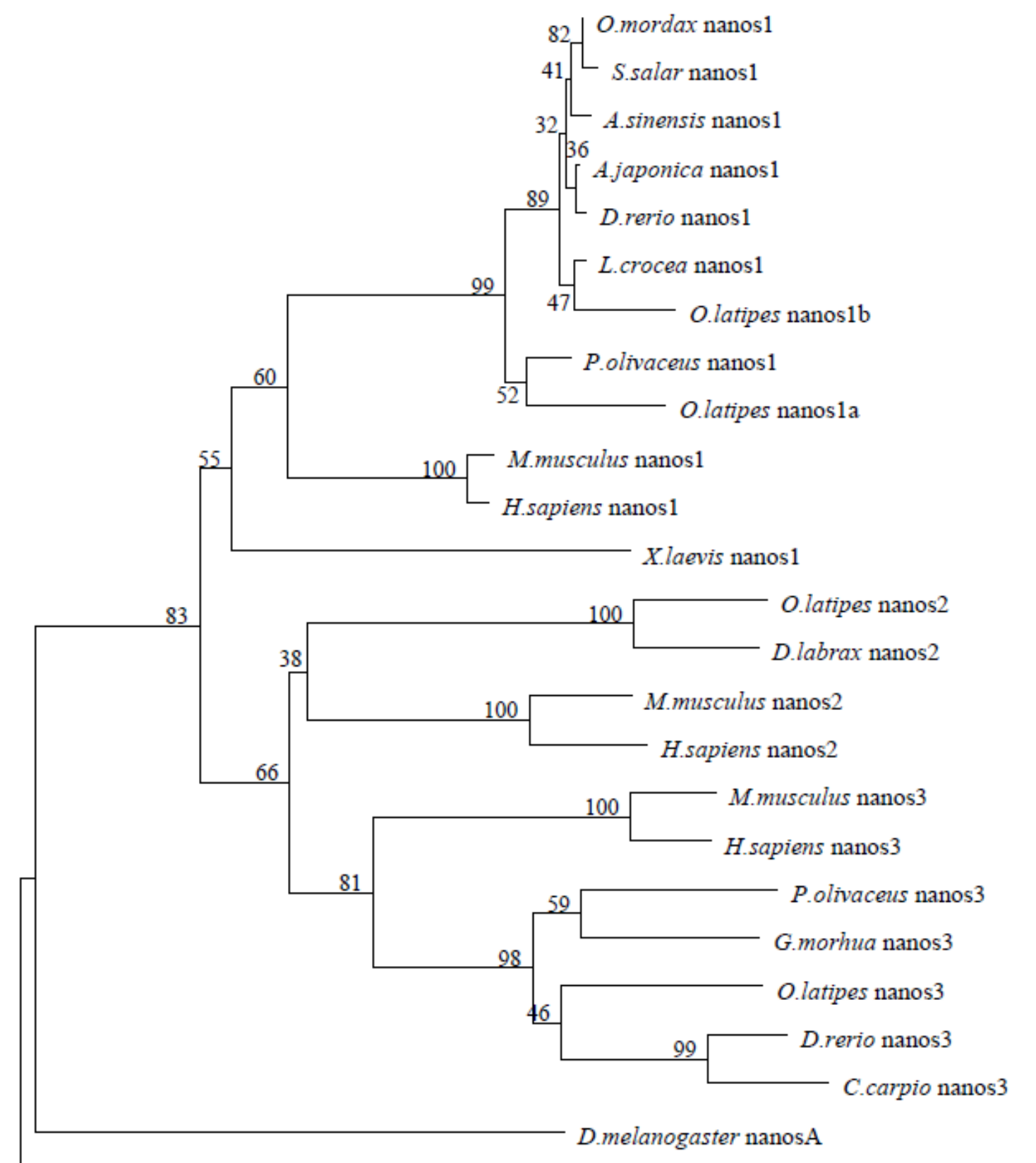

C.elegans nos 1

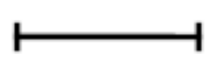

0.1

Figure 1B. Phylogenetic relationships of the olive flounder Nanos1 protein and nanos homologs in other species.

The GenBank accession numbers for the nanos homologs used in this analysis are as follows: $P$. olivaceus nanos1 (XXXXXX), $P$. olivaceus nanos3 (KR855714), Anguilla japonica nanos1 (AB674328.1), Larimichthys crocea nanos1 (KF690631.1), Osmerus mordax nanos1 (BT074904.1), Salmo salar nanos1 (NM_001141585.1), Oryzias latipes nanos1a (AB437935.1), O. latipes nanos1b (NM_001160469.1), O. latipes nanos2 (NM_001160447.1) ), O. latipes nanos3 (NM_001122828.1), Danio rerio nanos1 (XM_003199836.3), D. rerio nanos3 (AY052376.1), Homo sapiens NANOS1 (NM_199461.2), H. sapiens NANOS2 (NM_001029861.2), H. sapiens NANOS3 (NM_001098622.2), Mus musculus Nanos1 (NM_178421.3 ), M. musculus Nanos2 (NM_194064.2), M. musculus Nanos3 (NM_194059.2), Acipenser sinensis nanos1 (JQ410472.2), Cyprinus carpio nanos3 (AB576134.1), Gadus morhua nanos3 (HM451457.1), Dicentrarchus labrax nanos2 (FQ310508.3), Xenopus laevis nanos1 (NM_001088034.1), Drosophila melanogaster NanosA (NM_057310.4), and Caenorhabditis elegans nos1 (NM_063957.1). The sum of the optimal tree's branch length $=4.78793245$. The percentage of replicate trees in which the associated taxa clustered together are shown next to the branches (Felsenstein, 1985). The tree was drawn to scale, and the units of branch lengths are the same as those of the evolutionary distances used to infer the phylogenetic tree. The units of evolutionary distances represent the number of amino acid substitutions per site (Zuckerkandl \& Pauling, 1965). 


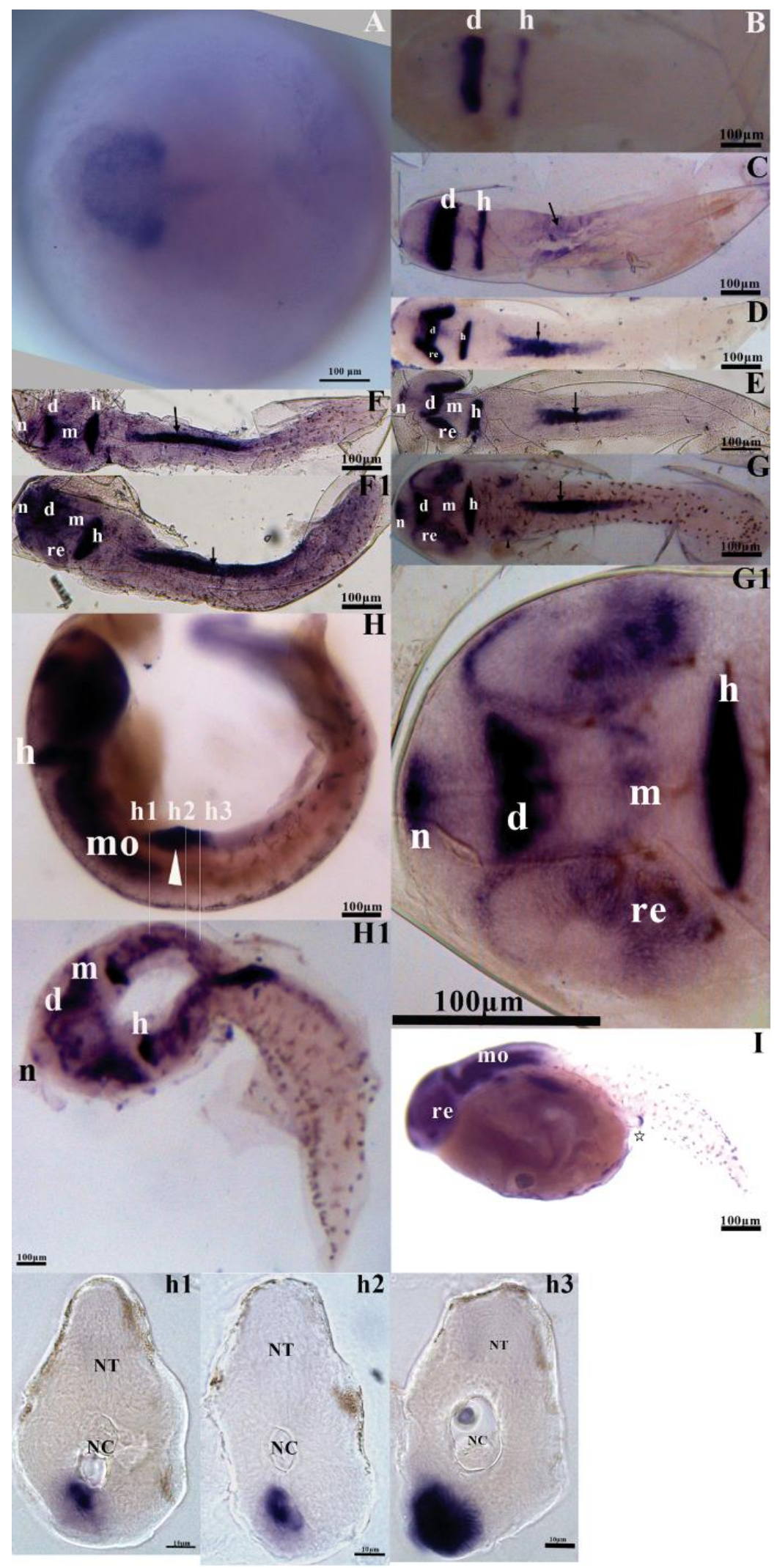

Figure 2. Spatial distribution of olive flounder nanos1 transcripts during embryogenesis.

Representative images of various developments stages. (A) $75 \%$ epiboly, top view, head to the left. (B) $22.75 \mathrm{hpf}$. (C) $24.25 \mathrm{hpf}$ (D) 25.75hpf. (E) $28.75 \mathrm{hpf}$. (F) $37.75 \mathrm{hpf}$ (G) $40.75 \mathrm{hpf}$, head to the left, dorsal view, F1, $37.75 \mathrm{hpf}$, head to the left, ventral view. G1, magnification of $\mathbf{G} . \mathbf{H}, \mathbf{H 1}, 50.75$ hpf. $\mathbf{H}$, side view. $\mathbf{H 1}$, dorsal view of head. h1, h2, h3, cross-section of $\mathbf{H}$, dorsal to top. I, hatching stage, head to the left, dorsal view. m, midbrain; d, diencephalon; h, hindbrain; re, retina; $n$, nose; mo, medulla oblongata. NT, neural tube; NC, notochord. (D-G) The black arrow indicates the trunk neural (which will later form the medulla), (G) the black arrowhead indicates the branchial $\operatorname{arch},(\mathbf{H})$ the white arrowhead indicates the abdomen, (I) the white star indicates the somatic gonadal cells. 


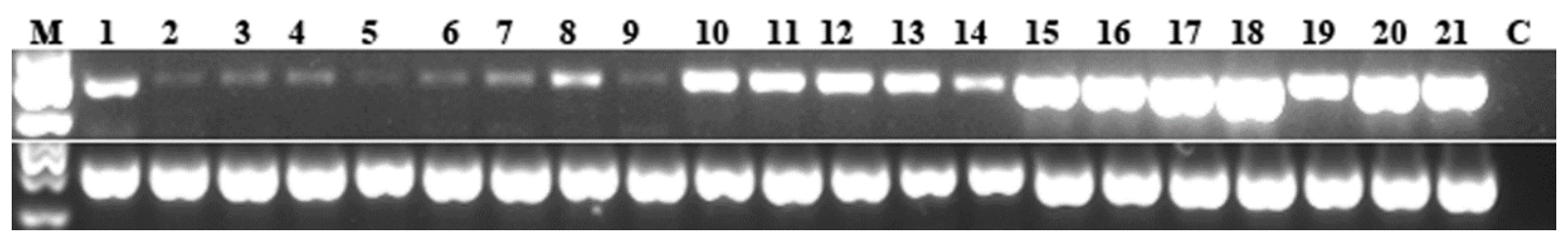

Figure 3. Reverse transcription-PCR analysis of nanos1 expression during olive flounder embryogenesis.

Up, nanos1; Down 8-actin. M, Marker; 1, unfertilized egg; 2, 1-cell; 3, 2-cell; 4, 4-cell; 5, 8-cell; 6, 16-cell, 7, 32-cell; 8, multicellular stage; 9 , blastula; $10,50 \%$ epiboly; $11,70 \%$ epiboly; 12 , 90\% epiboly,13, 22.75hpf; 14, 24.75hpf, 15, 26.hpf, 16, b31.hpf, 17, 37hpf, $18,43.45 \mathrm{hpf}, 19,51.45 \mathrm{hpf}, 20,56.45 \mathrm{hpf}$. 21, hatching stage; C, Blank control.

PCR (Figure 3). nanos1 was expressed at all the stages analyzed, including in unfertilized embryos, which suggested that nanos1 was maternally inherited. Prior to the blastula stage, expression was very low.

\section{Discussion}

In this study, we isolated the olive flounder nanos1 homolog and characterized its expression patterns during the process of embryonic development by in situ hybridization and RT-PCR.

It has been proposed that an additional fishspecific genome duplication (FSGD) event occurred during teleost evolution (Amores et al., 1998; Venkatesh, 2003). In medaka, there are two nanos1 homologs, nanos $1 a$ and nanos $1 b$, which are believed to have originated from a gene duplication event (Aoki et al., 2009). In our study, we isolated one nanos 1 homolog from the olive flounder. Our phylogenetic analysis showed that the olive flounder nanos1 homolog was most closely related to Chinese sturgeon nanos1 that to any other species, and clustered into a group that included most nanos1 of teleost fish, including medaka Nanos1b, whereas medaka nanos1a was in another cluster. Additionally, there were two Nanos1 homologs in other fish: the stickleback and the tetraboron (Aoki et al., 2009). Therefore, considering that the teleosts are believed to have undergone a genome-wide duplication event and the discovery of multiple nanos paralogues in other teleost fish, it is likely that there is another nanos 1 in the olive flounder.

The RT-PCR detected that the olive flounder nanos1 transcript in unfertilized embroys but the expression remained low until the blastula stage. This result showed that nanos1 mRNA is inherited maternally, as is the case in Drosophila, mouse, and Xenopus (Bergsten \& Gavis, 1999; Haraguchi et al., 2003; Lai, Zhou, Luo, Fox, \& King, 2011). The nanos1 mRNA of the olive flounder was not analyzed in the whole-mount in situ hybridization experiments until $50 \%$ epiboly, which coincided with the low expression levels observed by RT-PCR.

nanos1 transcripts have been detected in the nervous system of vertebrates such as frog, medaka, zebrafish, mouse, and human (Haraguchi et al., 2003; Aoki et al., 2009; Julaton \& Reijo Pera, 2011; Lai et al., 2011), with the function of nanos1 varying from species to species. For example, no significant neural defects were observed in Nanos1-deficient mice (Haraguchi et al., 2003), while Nanos was required for the formation of the peripheral nervous system in Drosophila (Ye et al., 2004; Brechbiel \& Gavis, 2008). In medaka, nanos1a and nanos $1 b$ showed different expression patterns in the nervous system, nanos $1 a$ was expressed in the caudal wall of the mesencephalon, part of the cerebellum, part of the diencephalon, the habenula, the rostral hypothalamus, part of the hypothalamus, and the peripheral ganglia. nanos $1 b$ was presented in the telencephalon, the proliferation zone of the retina, the optic tectum, and the optic vesicle.

In this study, the expression of nanos1 in the olive flounder exhibited a mixture of the nanos1a and nanos $1 b$ expression patterns previously observed in medaka (the expression was detected in the diencephalon, the proliferation zone of the retina, and the nose). The olive flounder nanos 1 was also expressed in the medulla oblongata similar to the expression patterns of mouse nanos1 (Haraguchi et al., 2003). Additionally, the mouse nanos1 showed a different expression pattern from that of medaka nanos1a or medaka nanos $1 b$, but similar to that of both medaka nanos1 (Aoki et al., 2009). Therefore, our data suggested that the function of nanos 1 might be speciesspecific. Further investigation is required to establish the role of the olive flounder nanos 1 in the development of the nervous system.

The olive flounder nanos1 was also expressed in the abdomen, which could represent the progenitor cells of the gut, similar to Drosophila, where nanos $A$ was expressed in the abdomen (Lehmann \& NussleinVolhard, 1991). nanos was expressed the midgut in Bombyx mori (Zhao et al., 2008), in the developing foregut of the polychaete Capitella spp. (Dill \& Seaver, 2008), and in the intestine of a snail (Ilyanassa obsoleta) (Rabinowitz, Chan, Kingsley, Duan \& Lambert, 2008). In adult Chinese sturgeons (A. sinensis), nanos1 was also expressed in the intestine (Ye et al., 2012). Thus, the expression of nanos in peripheral tissues may not only be conserved in invertebrates (Ye et al., 2012) but also in vertebrates.

nanos1 was mainly expressed in various somatic tissues of vertebrates (Jaruzelska et al., 2003; Haraguchi et al., 2003; Aoki et al., 2009;). However, its expression was also detected in germ cells of Xenopus (Mosquera, 
Forristall, Zhou, \& King, 1993; Lai et al., 2011;) and in the gonads of species such as Xenopus, mouse, and human (Haraguchi et al., 2003; Jaruzelska et al., 2003; Julaton \& Reijo Pera, 2011). In teleost, nanos1 transcripts were also detected in the gonads or germ cells. In medaka, nanos1a expression has been observed in the somatic cells that surround the meiotic germ cells (Aoki et al., 2009), while nanos1 transcripts were found in the gonads of adult Chinese sturgeons ( $A$. sinensis) (Ye et al., 2012). In the olive flounder, it was more likely that nanos1 was expressed in the somatic gonadal cells during the hatching stage. Thus, the function of nanos 1 in the germ cells or gonads of the olive flounder will require further elucidation.

\section{Conclusion}

In conclusion, the sequence of the olive flounder nanos1 homologue was conserved with those of other species. Nanos1 expression patterns have been shown to be species-specific, implying that nanos1 function could be both divergent and convergent depending on the species.

\section{Acknoledgments}

We thank Prof. Songlin Chen (Yellow Sea Fisheries Research Institute, Chinese Academy of Fishery Sciences) for providing genomic sequences of Japanese flounder nanos1. This work was supported by the National Natural Science Foundation of China (31672636, 31502146, 31972774) ,the Shandong Provincial Natural Science Foundation(2019GHY112007), China and the National High Technology Research and Development Program of China (863 Program: 2012AA10A402) and National infrastructure of fishery Germplasm resource. The funders had no role in study design, data collection and analysis, decision to publish, or preparation of the manuscript.

\section{References}

Amores, A., Force, A., Yan, Y.L., Joly, L., Amemiya, C., Fritz, A., Ho, R.K., Langeland, J., Prince, V., Wang, Y.L., Westerfield, M., Ekker, M., \& Postlethwait, J.H. (1998). Zebrafish hox clustersand vertebrate genome evolution. Science, 282, 1711-1714. http://dx.doi.org/10.1126/science.282.5394.1711

Aoki, Y., Nakamura, S., Ishikaw, Y., \& Tanaka, M. (2009). Expression and syntenic analyses of four nanos genes in medaka, Zoological Science, 26(2), 112-118. https://doi.org/10.2108/zsj.26.112

Asaoka-Taguchi, M., Yamada, M., Nakamura, A., Hanyu, K., \& Kobayashi, S. (1999). Maternal Pumilio acts together with Nanos in germline development in Drosophila embryos. Nature Cell Biology, 1, 431- 437. http://doi.org/ 10.1038/15666
Bergsten, S.E., \& Gavis, E.R. (1999). Role for mRNA localization in translational activation but not spatial restriction of nanos RNA. Development, 126,659-669.

Brechbiel, J.L., \& Gavis, E.R. (2008). Spatial regulation of nanos is required for its function in dendrite morphogenesis. Current Biology, 18, $745-750$.

https://doi.org/10.1016/j.cub.2008.04.033

Dill, K.K., \& Seaver, E.C. (2008). Vasa and nanos are coexpressed in somatic and germ line tissue from early embryonic cleavage stages through adulthood in the polychaete Capitella sp. I. Development Genes \& Evolution, 218, 453-463. https://doi.org/10.1007/s00427-008-0236-x

Extavour, C.G., Pang, K., Matus, D.Q., \& Martindale, M.Q. (2005). vasa and nanos expression patterns in a sea anemone and the evolution of bilaterian germ cell specification mechanisms. Evolution \& Development, 7, 201-215. https://doi.org/10.1111 /j.1525142X.2005.05023.x

Felsenstein, J. (1985). Confidence limits on phylogenies:An approach using the bootstrap. Evolution, 39, 783791.https://doi.org/10.1111/j.15585646.1985.tb00420.x

Haraguchi, S., Tsuda, M., Kitajima, S., Sasaoka, Y., NomuraKitabayashid, A., Kurokawa, K., \& Saga, Y. (2003). Nanos1: a mouse nanos gene expressed in the central nervous system is dispensable for normal development. Mechanisms of Development, 120,6: 721-731. https://doi.org/10.1016/S0925-4773(03)00043-1

Hayashi, Y., Hayashi, M., \& Kobayashi, S. (2004). Nanos suppresses somatic cell fate in Drosophila germ line. Proceedings of the National Academy of Sciences, USA, 101, $10338 \quad-\quad 10342 . \quad$ https://doi.org /10.1073/pnas.0401647101

Hiroshi, H., Shiget, K., Kodai, H., Keishi, N., Toshiyuk, I.S., Yutaka, T., \& Mamoru, S. (2009). Purification, crystallization and initial X-ray diffraction study of the zinc-finger domain of zebrafish Nanos. Acta Crystallographica, 65, 959-961. https://doi.org/10.1107/S1744309109032163

Jaruzelska, J., Kotecki, M., Kusz, K., Spik, A., Firpo, M., \& Reijo Pera, R.A. (2003). Conservation of a Pumilio-Nanos complex from Drosophila germ plasm to human germ cells. Development Genes \& Evolution, 213(3), 120-6. https://doi.org/10.1007/s00427-003-0303-2

Jiao, S., Tan, X., Li, M., Sui, Y., Du, S.J., You, F. (2015). The duplicated paired box protein 7 (pax7) genes differentially transcribed during Japanese flounder (paralichthys olivaceus) embryogenesis. Comparative Biochemistry and Physiology Part B: Biochemistry and Molecular Biology, 189, 62-68. https://doi.org/10.1016/j.cbpb. 2015.08.003

Julaton, V.T., \& Reijo Pera, R.A. (2011). NANOS3 function in human germ cell development. Human Molecular Genetics, 20, 2238-2250. https://doi.org/10.1093/hmg/ddr114

Kraemer, B., Crittenden, S., Gallegos, M., Moulder, G., Barstead, R., Kimble, J., \& Wickens, M. (1999). NANOS-3 and $\mathrm{FBF}$ proteins physically interact to control the sperm- oocyte switch in Caenorhabditis elegans. Current Biology, 9,1009 -1018. https://doi.org/10.1016/s09609822(99)80449-7

Lai, F., Zhou, Y., Luo, X., Fox, J., \& King, M.L. (2011). Nanos1 functions as a translational repressor in the Xenopus 
germline. Mechanisms of Development, 128, 153-163. https://doi.org/10.1016/j.mod.2010.12.001

Lehmann, R., \& Nusslein-Volhard, C. (1991). The maternal gene nanos has a central role in posterior pattern formation of the Drosophila embryo. Development, 112, 679-691.

Li, M., Tan, X., Jiao, S., Wang, Q., Wu, Z., You, F., \& Zou, Y. (2015). A new pattern of primordial germ cell migration in olive flounder Paralichthys olivaceus identified using nanos3. Development Genes \& Evolution,2254: 195-206. https://doi.org/10.1007/ s00427-015-0503-6

Mochizuki, K., Sano, H., Kobayashi, S., Nishimiya-Fujisawa, C., \& Fujisawa, T. (2000). Expression and evolutionary conservation of nanos-related genes in Hydra. Development Genes \& Evolution, 210: 591-602. https://doi.org/10.1007/s004270000105

Mosquera, L., Forristall, C., Zhou, Y., \& King, M.L. (1993). A mRNA localized to the vegetal cortex of Xenopus oocytes encodes a protein with a nanos-like zinc finger domain. Development,117:377-386.

Rabinowitz, J.S., Chan, X.Y., Kingsley, E.P., Duan, Y., \& Lambert, J.D. (2008). Nanos is required in somatic blast cell lineages in the posterior of a mollusk embryo. Current Biology, 18: 331-336. https://doi.org/10.1016/j.cub.2008.01.055

Saitou, N., \& Nei, M. (1987). The neighbor-joining method: a new method for reconstructing phylogenetic trees. Molecular Biology and Evolution, 44, 406-425. https://doi.org/10.1093/oxfordjournals.molbev.a04045 4

Shen, R., \& Xie, T. (2010). NANOS: a germline stem cell's Guardian Angel. Journal of Molecular Cell Biology, 2: 7677. https://doi.org/10.1093/jmcb/mjp043

Sievers, F., Wilm, A., Dineen, D., Gibson, T.J., Karplus, K., Li, W., Lopez, R., McWilliam, H., Remmert, M., Söding, J., Thompson, J.D., \& Higgins, D.G. (2011). Fast, scalable generation of high-quality protein multiple sequence alignments using Clustal Omega. Molecular Systems Biology, 7: 539. https://doi.org/10.1038/msb.2011.75
Subramaniam, K., \& Seydoux, G. (1999). nos-1 and nos-2, two genes related to Drosophila nanos, regulate primordial germ cell development and survival in Caenorhabditis elegans. Development, 126: 4861-4871.

Suzuki, A., Tsuda, M., \& Saga, Y. (2007). Functional redundancy among Nanos proteins and a distinct role of Nanos2 during male germ cell development. Development, 134. 77-83. https://doi.org/10.1242/dev.02697

Tamura, K., Stecher, G., Peterson, D., Filipski, A., \& Kumar, S. (2013). MEGA6: molecular evolutionary genetics analysis version 6.0. Molecular Biology and Evolution, 3012, 2725-2729. https://doi.org/10.1093/molbev/mst197

Temminck, C.J., \& Schlegel, H. (1846). Pisces. Parts 10-14. In: von Siebold PF (ed) Fauna Japonica. Lugduni, Batavorum, $184 \mathrm{pp}$

Tian, Y., Chen, S., Yan, A., \& Ji, X. (2004). Study on the embryonic development of Paralichthys olivaceus. Journal of Fisheries of China (Chinese), 28, 609-615.

Tsuda, M., Kiso, M., \& Saga, Y. (2006). Implication of nanos2$3^{\prime}$ UTR in the expression and function of nanos2. Mechanisms of Development, 123, 440-449. https://doi.org/10.1016/j.mod.2006.04.002

Tsuda, M., Sasaoka, Y., Kiso, M., Abe, K., Haraguchi, S., Kobayashi, S., \& Saga, Y. (2003). Conserved role of nanos proteins in germ cell development. Science, 301,12391241. https://doi.org/10.1126/science.1085222

Venkatesh, B. (2003). Evolution and diversity of fish genomes. Current Opinion in Genetics \& Development, 13, 588592. https://doi.org/10.1016/j.gde.2003.09.001

Wang, Z., \& Lin, H. (2004). Nanos maintains germline stem cell self-renewal by preventing differentiation. Science, 303, 2016-2019. https://doi.org/10.1126/science.1093983

Ye, H., Chen, X., Wei, Q., Zhou, L., Liu, T., Gui, J., Li, C.,\& Cao, H. (2012). Molecular and expression characterization of a nanos1 homologue in Chinese sturgeon, Acipenser sinensis. Gene,511: 285-92. https://doi.org/10.1016/j.gene.2012.09.005

Ye, B., Petritsch, C., Clark, I.E., Gavis, E.R., Jan, L.Y., \& Jan, Y.N. (2004). Nanos and Pumilio are essential for dendrite morphogenesis in Drosophila peripheral neurons. Current Biology, 14, 314-321. https://doi.org/10.1016/j.cub.2004.01.052

Zhang, Y., Tan, X., Zhang, P.-J., \&Xu, Y. (2006). Characterization of muscle regulatory gene, $M y o D$, from flounder Paralichthys olivaceus and analysis of its expression Patterns During Embryogenesis. Marine Biotechnology, 8,139-148. https://doi.org/10.1007/s10126-005-5042-0

Zhao, G., Chen, K., Yao, Q., Wang, W., Wang, Y., Mu, R., Chen, H., Yang, H., \& Zhou H., (2008). The nanos gene of Bombyx mori and its expression patterns in developmental embryos and larvae tissues. Gene Expression Patterns, 8, 254-260. https://doi.org/10.1016/j.gep.2007.12.006

Zuckerkandl, E., \& Pauling, L. (1965). Evolutionary Divergence and Convergence in Proteins. In: Bryson V, Vogel HJ (eds). Evolving Genes and Proteins: Academic Press. 97$166 \mathrm{pp}$. 